\title{
Safety Study on Blasting Vibration of Down Tunnel in Neighboring Villages
}

\author{
Chunchao Chen, Zhiyu Zhang, Zihao Tao, Jiguo Zhou, Bishu Zhang \\ Faculty of Land and Resources Engineering, Kunming University of Science and Technology, Kunming, China
}

\author{
Email address: \\ 592741625@qq.com (Chunchao Chen)
}

To cite this article:

Chunchao Chen, Zhiyu Zhang, Zihao Tao, Jiguo Zhou, Bishu Zhang. Safety Study on Blasting Vibration of Down Tunnel in Neighboring Villages. Engineering and Applied Sciences. Vol. 5, No. 1, 2020, pp. 15-21. doi: 10.11648/j.eas.20200501.13

Received: January 13, 2020; Accepted: February 3, 2020; Published: February 13, 2020

\begin{abstract}
Blasting is an effective methods of tunnel excavation, but blasting vibration damage will occur in the construction process. In order to study the blasting vibration of the downlink tunnel, the blasting vibration of the upper part of a tunnel in yunnan was monitored The results show that the vertical vibration velocity is higher than the other two axial vibration velocity, and there is obvious elevation amplification effect in the blasting vibration propagation process. In this test condition, the impact range of blasting vibration is $22 \mathrm{~m}$, which will not affect the village. According to HHT analysis, the blasting vibration energy is mainly concentrated in the low-frequency interval, while the high frequency interval vibration energy is small; The instantaneous response spectrum of blasting vibration energy can reflect the number of detonators used for the maximum single-end charge, and there is a surge of energy in the process of blasting vibration energy transmission. At the same time, the expansion of the air face can effectively reduce the transfer of blasting vibration energy. The results show that the propagation of blasting vibration energy can be effectively controlled by controlling the maximum charge of explosive and increasing the blank surface.
\end{abstract}

Keywords: The Blasting Vibration, Prediction of Blasting Vibration Velocity, HHT Analysis, Time-Frequency Characteristic

\section{Introduction}

With the construction of expressways in northwest China, the interaction between expressways and villages becomes more and more common. Tunnel blasting has become an effective means of tunneling down the village, but the blasting vibration generated during the tunnel blasting construction will have a certain impact on the upper village, which requires that the tunnel blasting construction not only guarantees the safety of the upstream village, but also guarantees the orderly and progressive construction. The propagation of blasting vibration is not only related to the quantity of explosives, but also to the nature of rock mass [1], which requires us to make a thorough study of the propagation of blasting vibration.

Using the theory of explosion dynamics and elastic wave, Lou xiaoming [2] constructed the calculation model of particle vibration velocity in the surrounding rock of differential blasting tunnel, and pointed out that distance, charge and time were the main influencing factors of blasting vibration. Nguyen et al [3] used numerical analysis and field tests to carry out research on the impact of blasting vibration, and the test results showed that the genetic algorithm has a good effect in blasting vibration prediction. Through the blasting model test, $\mathrm{Xu}$ jingui [4] pointed out that the blasting vibration decreased with the increase of horizontal distance and blasting center distance, and pointed out that the blasting vibration velocity of the sloping top was obviously higher than that of other positions. On the basis of the traditional Sadovsky formula, Ye haiwang [5] introduced terrain influencing factors such as elevation difference and horizontal distance by using dimensional analysis method. Compared with the traditional prediction formula, the velocity prediction formula constructed has higher accuracy. Yu jianxin [6] made a regression analysis of the blasting vibration velocity of the upper and lower cross tunnels, and obtained the Sadovsk formula of the peak vibration velocity through calculation. By using this formula, the maximum charge weight of Cut hole and safety distance were obtained. Yang shan [7] used simple linear regression and binary linear regression to analyze the measured data of a vibration, determined the correlation coefficient of Sadovsky under different influencing factors, and obtained the safety criterion of blasting vibration peak value. R. p. dehakal [8] analyzed 
the vibration failure of blasting and pointed out that the low-frequency particle would have shear failure due to its large vibration displacement and small acceleration. Qiu xianyang [9] used Matlab to reveal the time-frequency characteristics of vibration signals at different differential intervals. The results showed that in blasting design, the dosage between adjacent segments should be the same as far as possible, and the energy reduction rate of superposition signals at the same differential interval decreases. When reaching a certain number of segments, the energy reduction effect will not be obvious. Zong qi [10] used HHT method and EMD method to analyze blasting seismic waves in coal mine roadway, and put forward countermeasures to reduce blasting seismic effect.

In order to analyze the blasting vibration safety of downlink tunnel in a village, the blasting vibration monitoring is carried out for two blasting constructions of downlink tunnel in a village. At the same time, the measured blasting vibration is analyzed by using Sadovsky analysis formula and Matlab to obtain the blasting vibration velocity prediction formula, blasting vibration influence distance critical value, and blasting vibration energy spectrum.

\section{Engineering Situation}

A highway tunnel is constructed according to grade III and grade IV of surrounding rock, and the construction method of upper and lower sections of positive steps is adopted. Figure 1 shows the design drawing of blasting hole network on the Step profile; No. 2 rock ammonium nitrate explosive was used as the detonating charge package, and non-electric detonator was used as the detonating charge package. The periphery hole were charged with uncoupled spacer charge, while the other holes were charged with continuous uncoupled spacer. The hole was filled with clay gun-mud with a length of $30 \mathrm{~cm}$. Cut hole is the maximum single stage charge, with a total of 10 holes, including 1 and 3 stages of initiation. During the construction of the tunnel, it is necessary to cross the adjacent villages directly below. The villages are located on the hillside with obvious height difference, and the houses are mostly roughcast house and brick houses. When the blasting is carried out, the village houses have an obvious sense of vibration. In order to further analyze the impact of the blasting construction of downlink tunnel on the superstructure, the blasting vibration generated during the blasting construction of the upper steps is monitored and quantified.

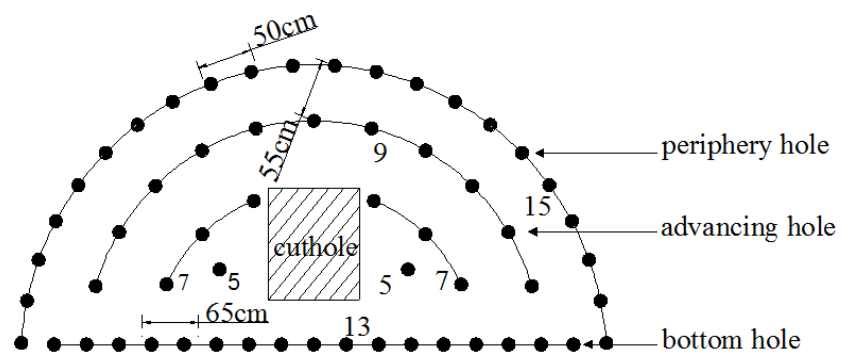

Figure 1. The blasthole layout.

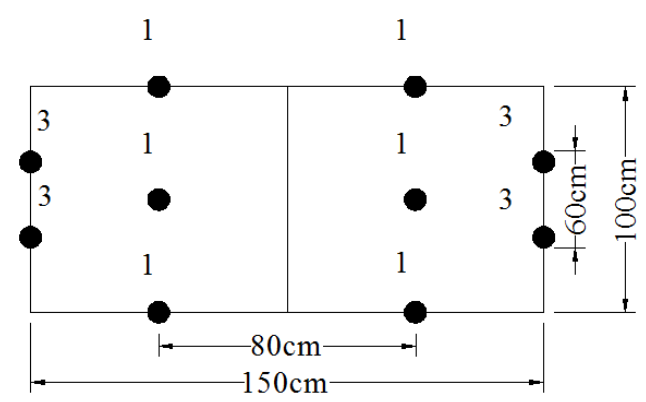

Figure 2. The cuthole layout.

\section{Blasting Vibration Monitoring}

\subsection{Blasting Vibration Measuring Point Arrangement}

It is clearly stipulated in "safety regulations for blasting» [11] that there are different safety evaluation standards for different constructions. The village is located on a hillside with dense houses, mostly of blank square and brick-concrete structures. The safety criteria are shown in table 1 .

Table 1. Safety permissible standard for blasting vibration.

\begin{tabular}{|c|c|c|c|}
\hline \multirow{2}{*}{ Protection object } & \multicolumn{3}{|c|}{ Critical value of vibration velocity $\mathrm{v} / \mathrm{cm} \cdot \mathrm{s}^{-1}$} \\
\hline & f $\leq 10 \mathrm{~Hz}$ & $10 \mathrm{~Hz}<\mathrm{f} \leq 50 \mathrm{~Hz}$ & $f>50 H z$ \\
\hline Caves, Roughcast house, Rubble houses & $0.15 \sim 0.45$ & $0.45 \sim 0.9$ & $0.9 \sim 1.5$ \\
\hline General civil building & $1.5 \sim 2.0$ & $2.0 \sim 2.5$ & $2.5 \sim 3.0$ \\
\hline
\end{tabular}

The blasting point of the tunnel is directly below the village. During the excavation of the tunnel, the amount of explosives used in the excavation of the upper section is much larger than that used in the lower section. Therefore, blasting vibration monitoring is carried out for the two blasts of the upper section. The topological nubox- 8016 vibration monitor of Sichuan province (see figure 2) was used to carry out blasting vibration monitoring. The measuring points were arranged on the foundation of village houses, and 6 measuring points were arranged at a time. See figure 4 for the specific arrangement of measuring points.

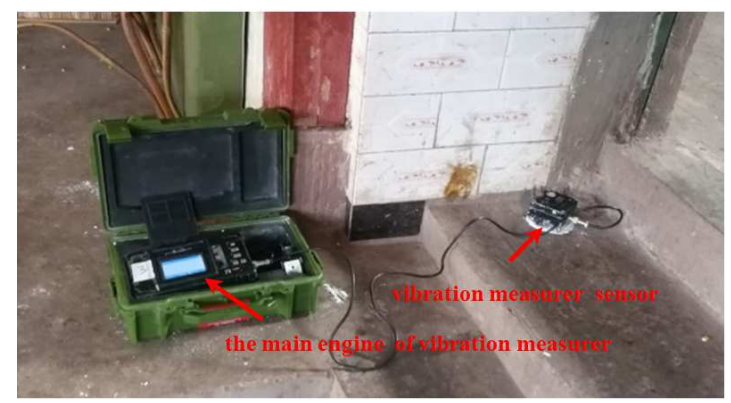

Figure 3. $N U B O X-8016$ vibration monitor. 


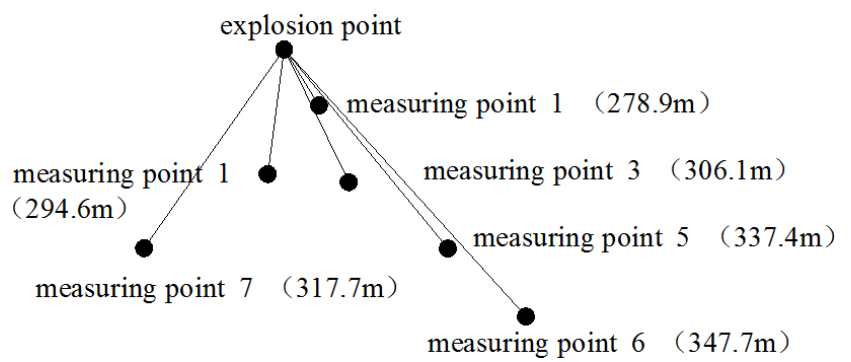

Figure 4. The layout of Monitor point.

\subsection{Monitoring Results}

Nubox-8016 vibration monitor was used to monitor the blasting vibration generated by the two upper step blasting. A total of 12 sets of test data were obtained through the two monitoring, and the 12 sets of measured data were output and recorded in table 2. According to the data in table 2, the blasting vibration velocity is distributed in the range of $0.024 \mathrm{~cm} / \mathrm{s} \sim 0.095 \mathrm{~cm} / \mathrm{s}$, and the vibration frequency is distributed in the range of $6.1 \mathrm{hz} \sim 141.48 \mathrm{hz}$. The blasting vibration velocity in the vertical direction is obviously higher than the particle vibration velocity in other directions, and there is an obvious elevation amplification effect in the vertical direction. Through analysis, it can be known that the blasting vibration has the greatest impact on the vertical direction of the building.

Table 2. The data of blasting vibration.

\begin{tabular}{|c|c|c|c|c|c|c|c|}
\hline \multirow{2}{*}{$\begin{array}{l}\text { the number of } \\
\text { blasting }\end{array}$} & \multirow[b]{2}{*}{ measuring points } & \multicolumn{3}{|c|}{ vibration velocity / $\left(\mathrm{cm} \cdot \mathrm{s}^{-1}\right)$} & \multicolumn{3}{|c|}{ vibrational frequency / $\mathrm{Hz}$} \\
\hline & & $\begin{array}{l}\text { radial } \\
\text { direction }\end{array}$ & $\begin{array}{l}\text { Tangential } \\
\text { direction }\end{array}$ & $\begin{array}{l}\text { vertical } \\
\text { direction }\end{array}$ & $\begin{array}{l}\text { radial } \\
\text { direction }\end{array}$ & $\begin{array}{l}\text { tangential } \\
\text { direction }\end{array}$ & $\begin{array}{l}\text { vertical } \\
\text { direction }\end{array}$ \\
\hline \multirow{5}{*}{$1 \#$} & 1 & 0.04 & 0.044 & 0.086 & 39.67 & 40.89 & 40.4 \\
\hline & 2 & 0.038 & 0.042 & 0.083 & 39.03 & 18.92 & 61.03 \\
\hline & 3 & 0.031 & 0.035 & 0.07 & 21.2 & 63.6 & 61.03 \\
\hline & 4 & 0.03 & 0.033 & 0.065 & 21.97 & 6.10 & 15.25 \\
\hline & 5 & 0.028 & 0.032 & 0.06 & 40.28 & 21.36 & 18.31 \\
\hline \multirow{6}{*}{$2 \#$} & 1 & 0.039 & 0.047 & 0.095 & 44.55 & 41.50 & 45.16 \\
\hline & 2 & 0.031 & 0.045 & 0.086 & 18.31 & 6.10 & 15.86 \\
\hline & 3 & 0.03 & 0.041 & 0.075 & 5.49 & 6.10 & 18.31 \\
\hline & 4 & 0.027 & 0.042 & 0.079 & 40.89 & 44.55 & 18.31 \\
\hline & 5 & 0.024 & 0.034 & 0.064 & 146.48 & 6.10 & 23.6 \\
\hline & 6 & 0.025 & 0.031 & 0.065 & 28 & 63.8 & 17.7 \\
\hline
\end{tabular}

\section{The Analysis of Blasting Vibration Results}

\subsection{Sadofsky Regression Analysis}

Under the action of blasting vibration wave, the displacement of ground building particle increases and damages the house. The damage degree of blasting seismic wave to the house mainly depends on the blasting vibration velocity and frequency of the particle at the house. The houses selected by this vibration monitoring point are mostly blank houses and brick-concrete houses. It can be seen from table 2 that the blasting vibration appears amplification effect in the vertical propagation process, and the blasting vibration velocity is significantly higher than other axial velocities. At the same time, the tunnel excavation process is located directly below the village, so obvious earthquake is likely to occur during the excavation and construction process, affecting the normal life of residents. In order to further quantitatively analyze the impact of blasting vibration on the superstructure of the tunnel, the velocity of blasting vibration in the direction of each axis is analyzed by Sadofsky regression. On the premise of determining the propagation law of blasting vibration velocity, the safe distance under the safety allowable standard of blasting vibration is further determined.
In the process of blasting vibration propagation, the maximum single-stage charge and blasting core distance are the main factors that affect the blasting vibration velocity. Mathematical statistical analysis method and Sadofsky formula are used to conduct regression analysis on the measured vibration data. The regression formula is as follows:

$$
v=K\left(\frac{\sqrt[3]{Q}}{R}\right)^{\alpha}
$$

Where, $\mathrm{v}$ is the blasting vibration velocity in a direction of the monitoring point, $\mathrm{cm} / \mathrm{s}$; $\mathrm{Q}$ is the maximum single stage charge of blasting, $\mathrm{Kg}$; $\mathrm{R}$ is the linear distance from the detonation center to the measuring point, $\mathrm{m}$; $\mathrm{K}$, where are the site coefficients and attenuation coefficients related to the geological conditions and topography between the measuring point and the measuring point from the detonation center.

For the convenience of analysis, the least square method is used to linearize formula (1), and the logarithm of both sides of equation (1) is taken to linearize it, namely:

$$
\ln v=\ln K+\alpha \ln \left(\frac{\sqrt[3]{Q}}{R}\right)
$$

Make $\operatorname{lnv}=y, \ln K=b, \ln \left(\frac{\sqrt[3]{\mathrm{Q}}}{\mathrm{R}}\right)=\mathrm{x}, \alpha=\mathrm{a}$ 
Formula (2) is translated into:

$$
\mathrm{y}=b+a x
$$

The values of $a$ and $b$ were calculated by mathematical statistics.

$$
\begin{gathered}
\mathrm{a}=\frac{l_{x y}}{l x x} \\
\mathrm{~b}=\bar{y}-a \bar{x}
\end{gathered}
$$

Type: $\quad l_{x y}=\sum_{i}^{n} x_{i} y_{i}-n \bar{x} \bar{y} \quad ; \quad l_{x x}=\sum_{i}^{n} x_{i}^{2}-\mathrm{n} \bar{x}^{2}$; $l_{y y}=\sum_{i}^{n} y_{i}^{2}-n \bar{y}^{2}$

The formula was tested by $\mathrm{r}$ test method, and the sample correlation coefficient was:

$$
\mathrm{r}=\frac{|l x y|}{\sqrt{l_{x x} \cdot l_{y y}}}
$$

When $r>r(n-2)$, the linear correlation is considered significant, otherwise it is not significant.

The data in table 2 were transformed according to formula (2), and the least square method was used to fit them, and the values of $\mathrm{k}$ and values of different gun orders were solved. The $r$ test method was used to test their correlation, which was recorded in table 3 . At the same time, the fitting curve and the vibration velocity in different coaxial directions were plotted in the same coordinate, as shown in figure 5.

Table 3. The values of $k$, $x$, and $r$ in different vibration directions.

\begin{tabular}{lllll}
\hline the number of blasting & $\mathbf{k}$ & $\boldsymbol{\alpha}$ & $\mathbf{r}$ & $\mathbf{r}_{\mathbf{0 . 0 2}}(\mathbf{4})$ \\
\hline \multirow{3}{*}{$1 \#$} & 307.9 & 1.98 & 0.961 & 0.882 \\
& 214.8 & 1.88 & 0.963 & 0.882 \\
& 419.9 & 1.88 & 0.968 & 0.882 \\
$2 \#$ & 345.8 & 2.03 & 0.952 & 0.882 \\
& 232.8 & 1.87 & 0.953 & 0.882 \\
& 304.6 & 1.79 & 0.958 & 0.882 \\
\hline
\end{tabular}

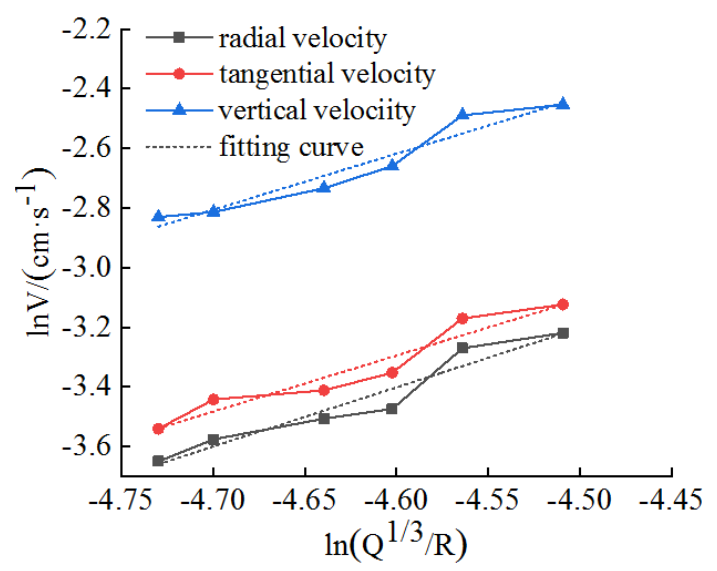

(a) First blast

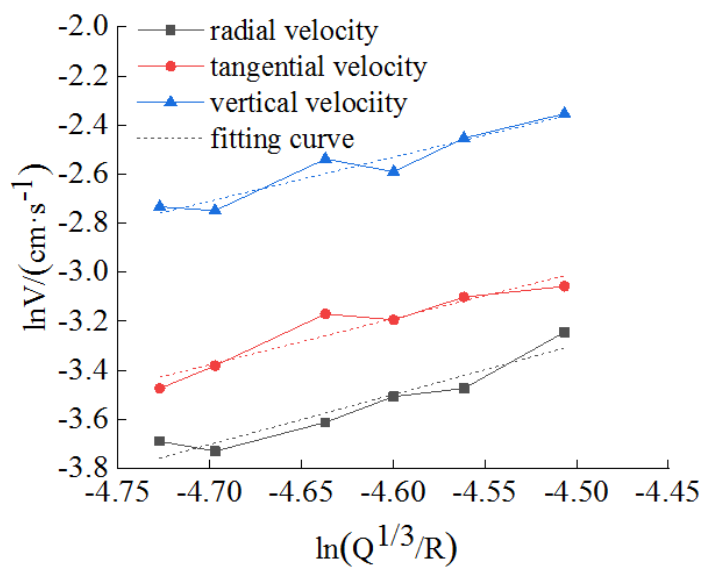

(b) second blast

Figure 5. Relationship curve and fitting curve between natural $\ln \left(Q^{I / 3} / R\right)$ and $\ln v$.

As can be seen from figure 5, the variation law of blasting vibration velocity in the direction of the three axes is basically consistent. As the distance increases, the blasting vibration velocity gradually decreases, and the impact of blasting vibration on houses and buildings also gradually decreases. The radial and tangential blasting vibration velocity is obviously lower than the vertical blasting vibration velocity, and the radial blasting vibration velocity is the smallest. Through analysis, it can be seen that the vertical particle vibration velocity has obvious elevation amplification effect, and has the greatest impact on the house, while the radial blasting vibration velocity has the least impact on the house. Under the confidence degree of 0.02 , the Sadovsky regression formula with each axis upward has a good fitting degree.

In order to further analyze the impact of blasting vibration on the building, the influence range of blasting vibration is predicted by the Sadofsky formula fitting and the critical value of blasting vibration velocity of blank and brick houses in table 1. In the above analysis, it can be seen that the vertical vibration velocity has the greatest impact on the house. The critical value of blasting vibration velocity of the blank house and the brick concrete house is $0.15 \mathrm{~cm} / \mathrm{s}$ and $1.5 \mathrm{~cm} / \mathrm{s}$, respectively, is put into equation (7) and equation (8), and the impact range of blasting vibration is $21.53 \mathrm{~m}$, $21.52 \mathrm{~m}, 21.71 \mathrm{~m}$ and $21.69 \mathrm{~m}$, respectively. The results show that the upper village is not in the vibration influence range, so it can be considered that the blasting vibration generated by the tunnel blasting construction will not affect the adobe house and brick house.

$$
\begin{aligned}
& R=\sqrt[3]{28.92}-\frac{\frac{v}{419.9}}{\mathrm{e}^{1.88}} \\
& R=\sqrt[3]{29.16}-\frac{\frac{v}{304.6}}{\mathrm{e}^{1.79}}
\end{aligned}
$$




\subsection{HHT Analysis of Blasting Vibration Waveform}

Through the above analysis, it can be seen that the blasting vibration value of downlink tunnel in the village reaches the maximum at the measuring point 1 , and the blasting vibration velocity in the vertical direction is greater than that in other axial directions. Then, the vertical vibration velocity of the measuring point 1 of the second gun is selected for HHT analysis, and the blasting vibration signal is shown in figure 5. In 1998, Huang et al [12]. proposed the HHT analysis method, which has good adaptability and has been widely used in the field of blasting vibration [13-15]. In this paper, HHTT analysis method is used to analyze the obtained blasting vibration signal, and then the vertical vibration velocity of the second gun measuring point 1 is selected for HHT analysis. The blasting vibration signal is shown in figure 6.

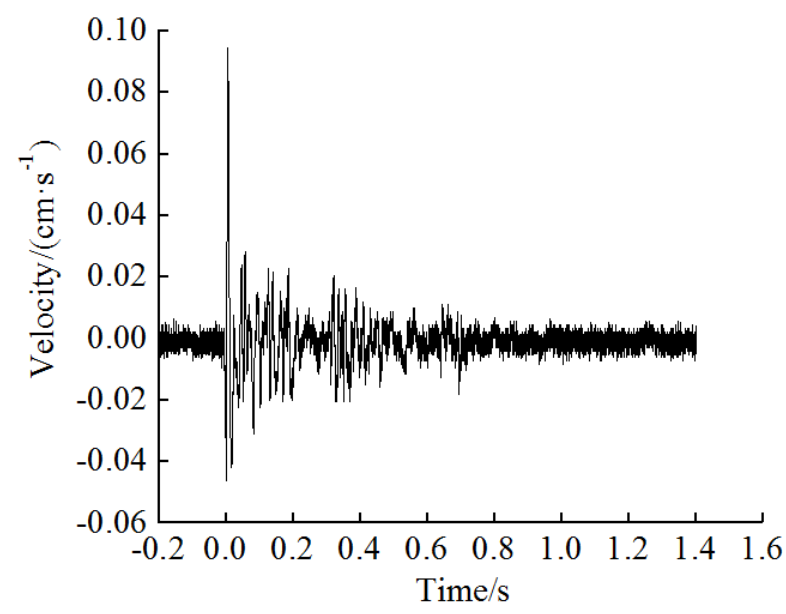

Figure 6. The velocity - time curve of blasting vibration of monitor 1 .

EMD decomposition of this waveform was conducted by Matlab, and 12 IMF components with different frequencies were obtained, as shown in figure 7. The frequency of B1 B12EMD components decreases from top to bottom, and the last one is the monotone residual component. It can be seen from figure 6 that the frequency of B1 B2EMD components is too high, which is determined as noise interference. The frequency of B4 B8 components is reduced, and the vibration intensity is greater than other components, which are the main components of the actual waveform. Among them, B4 and B5 are the closest to the measured waveform. Through analysis, it can be determined that B4 and B5 are the characteristic components of the measured waveform. When B9 B11, the blasting vibration velocity begins to decrease and the frequency is also in the low frequency stage. Compared with the measured data, B9 B11 are the low frequency components of the measured vibration. $\mathrm{B} 12$ is the monotone function of residual component, the component frequency and vibration value are no longer obvious, and it is the component of the average level of measured data, without Hilbert change.
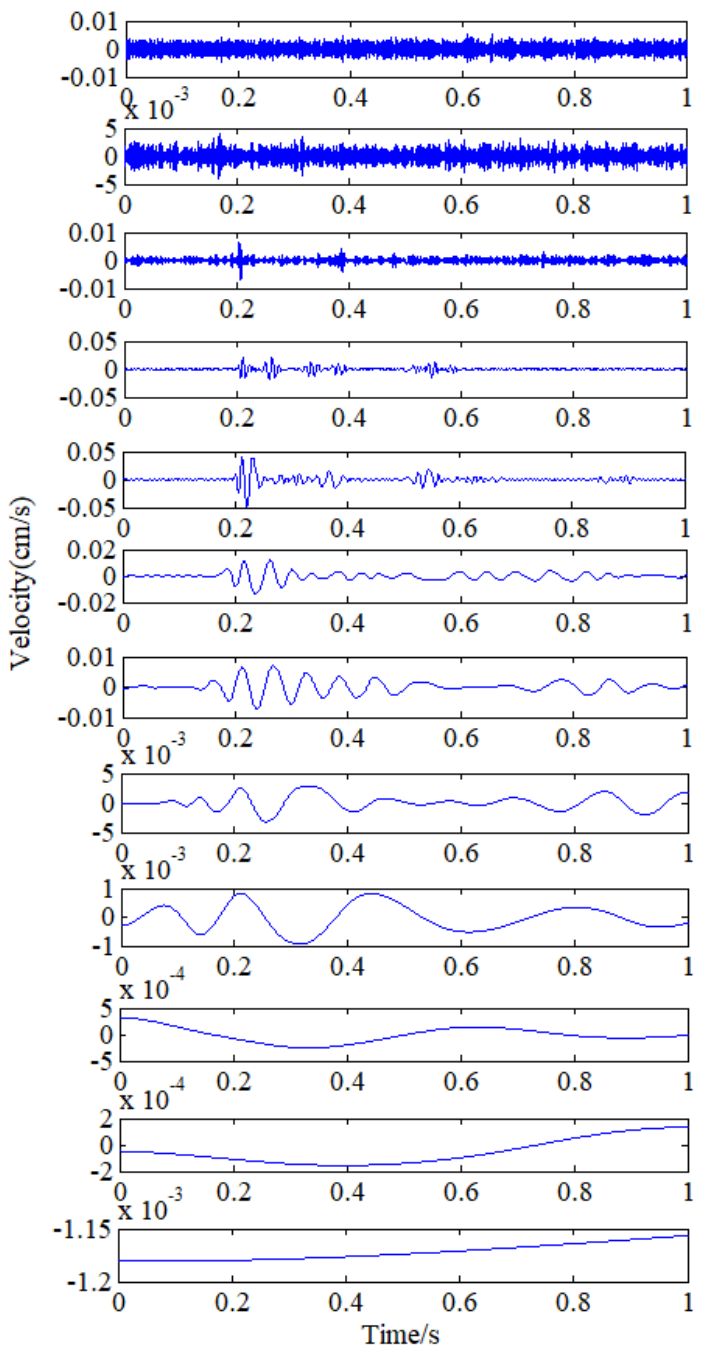

Figure 7. EMD decomposition.

In order to further analyze the EMD component, Hilbert changes were made to the B4 B11 components to obtain the 3DHilbert spectrum, and the corresponding 3D energy diagram was drawn, as shown in figure 8. According to figure 8 , the measured blasting vibration frequency is mainly distributed within $200 \mathrm{~Hz}$, among which the blasting vibration frequency is mainly concentrated in the range of $30 \mathrm{~Hz} \sim 80 \mathrm{~Hz}$, and the blasting vibration energy reaches the maximum value at $70 \mathrm{~Hz}$. In the 3DHilbert spectrum, the blasting vibration energy is a decreasing process with the increase of time. The blasting vibration energy is mainly concentrated in the interval of $0.3 \mathrm{~s} \sim 1 \mathrm{~s}$. At $0.3 \mathrm{~s}$, the blasting vibration energy reaches the maximum value. The blasting vibration energy decreases from $0.3 \mathrm{~s}$, and reaches the minimum value at $1 \mathrm{~s}$. Tunnel section on Cut holes using 10 detonator initiation, as you can see from the $3 \mathrm{D}$ hilbert spectrum, in $0.3 \mathrm{~s} \sim 1 \mathrm{~s}$ interval respectively for every 10 energy peak detonator initiation energy superposition, when detonator detonating, will with a surge in energy, detonator detonating initiation energy of blasting vibration peak, as further stimulate of detonators, blasting vibration energy decreases. Through the analysis of $3 \mathrm{D}$ Hilbert spectrum, it can be seen that the excitation of each detonator is accompanied by a surge of 
energy. When the detonator starts to explode gradually, the blasting vibration energy decreases gradually.

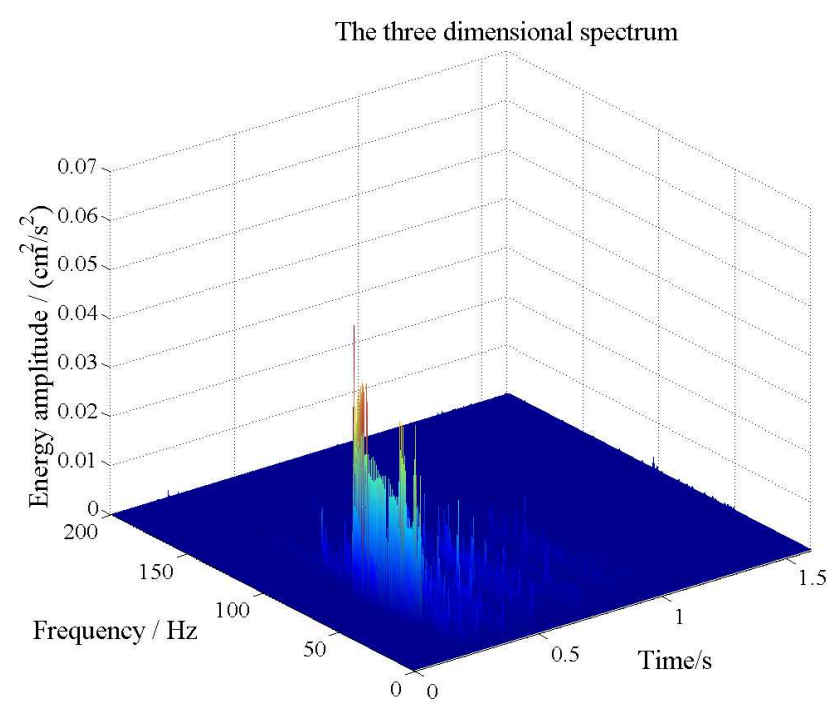

Figure 8. 3D Hilbert spectrum.

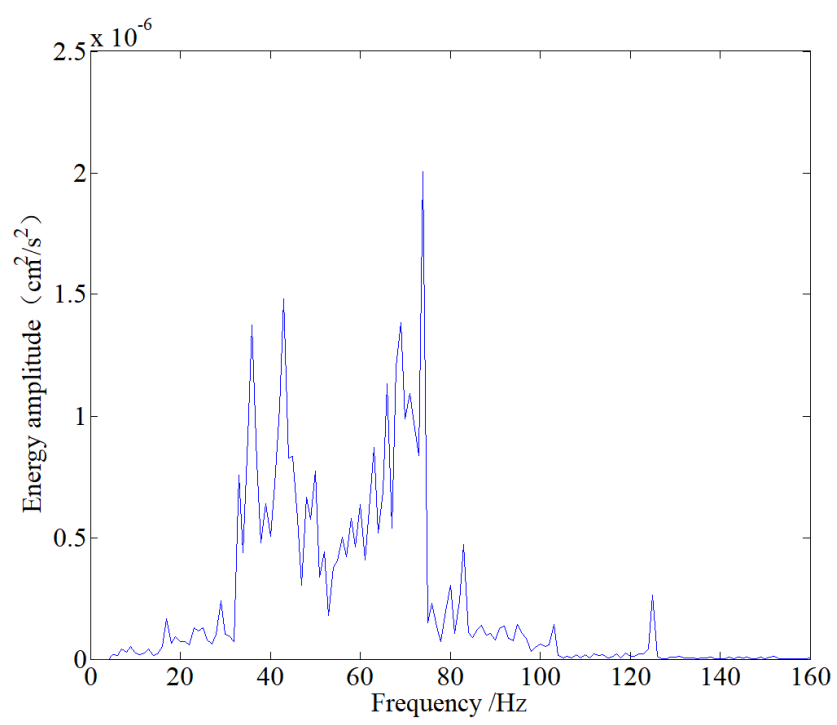

Figure 9. Measured waveform marginal spectrum.

Hilbert marginal spectrum can be obtained by integrating 3D Hilbert spectrum against time, as shown in figure 9. The marginal spectrum can reflect the energy amplitude distribution in the whole instantaneous frequency process, show the change law of the energy amplitude of the whole instantaneous frequency, and also reflect the relationship between the frequency distribution in the original signal and the blasting energy. In the measured blasting vibration signal frequency band, the energy amplitude of the low-frequency signal frequency band is larger, which is the main component of the blasting vibration. It also indicates that the blasting vibration energy is mainly concentrated in the low-frequency band. According to the marginal spectrum, the blasting vibration energy amplitude reaches the maximum value when the frequency is $75 \mathrm{~Hz}$. With the increase of frequency, the blasting vibration energy gradually decreases. In the high frequency band, the blasting vibration energy is relatively small overall, and the impact on the surrounding is relatively small. Through the analysis of the marginal spectrum, it can be seen that the high amplitude energy of blasting vibration is mainly concentrated in the low frequency section, and the energy amplitude in the high frequency section is relatively small, and the damage effect is also small.

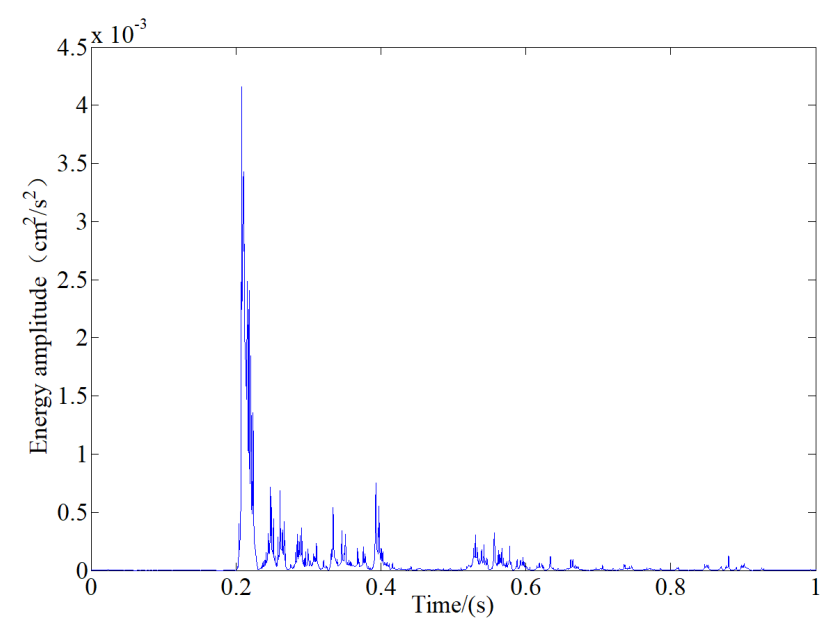

Figure 10. Instantaneous energy spectrum.

The instantaneous energy of blasting vibration can directly reflect the time-varying energy distribution of blasting vibration. The instantaneous energy diagram of blasting vibration can be obtained by frequency integration of $3 \mathrm{D}$ Hilbert spectrum in figure 10. Figure 10 reflect the law of blasting vibration energy at different moments of reaction measurement point 1 . The blasting vibration energy at $0.2 \mathrm{~s} \sim$ $0.3 \mathrm{~s}$ is the largest, which is the blasting vibration energy generated by the cut hole initiation. When $0.2 \mathrm{~s} \sim 04 \mathrm{~s}$, with the blasting vibration propagating in the rock mass medium, the vibration energy gradually decreases, and the propagation medium has certain unevenness and complexity, which is easy to influence the blasting vibration. When $0.2 \mathrm{~s} \sim 0.3 \mathrm{~s}$, the vibration energy value is the initiation effect of 1 section of detonator, and the energy change of $0.3 \mathrm{~s} \sim 0.4 \mathrm{~s}$ is the initiation effect of 3 sections of detonator. Compared with the vibration energy of the detonator in section 3 , since the strength of the rock mass around the Cut hole is relatively large, and there is no air surface, the detonation energy generated by the detonator in section 1 is larger, and the influence is also relatively large. In the process of blasting vibration propagation, there are 10 times of energy surge, which is due to the superposition of detonator energy during the blasting process of Cut hole, and the energy surge can well reflect the number of common detonators in Cut hole. When $0.4 \mathrm{~s} \sim 0.55$, there is delay time in blasting. Meanwhile, the blasting vibration energy can be effectively reduced to the outer surface. Blasting excavation hole, periphery hole and bottom hole in turn, blasting vibration energy is also relatively reduced due to the further expansion of the air surface and more energy is used for the fracture of rock mass and the escape of explosive gas. The blasting vibration energy is 
proportional to the vibration velocity. The higher the energy, the higher the blasting vibration velocity and the larger the blasting vibration destruction effect. The Maximum single charge and the surface also have a certain influence on the blasting vibration. When the maximum single stage charge increases, the blasting vibration velocity also increases. At the same time, the expansion of the surface can effectively reduce the propagation of blasting vibration energy.

\section{Conclusion}

Based on the prediction and analysis of the measured blasting vibration velocity on the upper steps of the downslope tunnel of the village by Sadofsky formula, it can be seen that the radial, tangential and vertical $\mathrm{k}$ values of the first blasting vibration are 307.9, 214.8 and 419.9, respectively, and the values are 1.98, 1.88 and 1.88, respectively. The radial, tangential and vertical $\mathrm{k}$ values of the second blasting vibration are 345.8, 232.8 and 3.4.6, respectively. The values are $2.03,1.87$ and 1.79 , respectively.

Under the terrain condition of downlink tunnel, the blasting vibration has obvious elevation amplification effect, and the vertical blasting vibration velocity is obviously higher than the other two axial vibration velocities. Meanwhile, the distance affected by blasting vibration is about $22 \mathrm{~m}$ according to the fitting formula of the measured data of Sadofsky formular, and the upper village will not be affected by blasting vibration.

blasting vibration energy in the high frequency range is relatively small, and the high energy of blasting vibration is mainly concentrated in the low frequency range of $30 \mathrm{~Hz} \sim 80 \mathrm{~Hz}$; there were 10 energy surges in the range of $0.2 \mathrm{~s}$ to $0.4 \mathrm{~s}$, which reflected the use of 10 detonators in the Cut hole, and the increase of air surface was conducive to reducing the effect of blasting vibration energy.

\section{References}

[1] Hao Hong, Wu Yaokun, Ma Guowei. Characteristics of surface ground motions induced by blasts in jointed rock mass $[\mathrm{J}]$. Characteristics of surface ground motions induced by blasts in jointed rock mass, 2001 (21): 85-98.

[2] Lou Xiaoming, Zhen Junjie, Ma Jianjun, Cai Lujun. Study on Blasting Vibration Velocity in Tunnel [J]. NONFERROUS METALS (Mining section), 2007, 59 (3): 31-34.

[3] Nguyen. Hoang, Choi. Yosoon, Bui Xuan-nam. Predicting
Blast-induced Ground Vibration in Open-pit Mines Using Vibration Sensors and Support Vector Regression-based Optimization Algorithms [J]. Sensors (basel, Switzerland), 2019, 20 (1): 20-60.

[4] Xu Jingui, Pu Chuanjin, He Gaowei, Xiao Dingjun, Feng Yangyang. Experimental study on propagation of side slope of blasting vibration of mountain-adjacent tunnel [J]. Nonferrous Metals (Mine Section) 2018, 70 (3): 51-58, 112.

[5] Ye Haiwang, Yuan Erjun, Lei Tao, Long Mei. Blasting Vibration Peak Particle Velocity Prediction Formula Based on Dimensional Analysis Method [J]. Metal Mine 2019 (5): 56-61.

[6] Yu Jianxin, Chen Weizhon, Yang Jianping, Yang Fan, Li Ming, Kuang Yuelin, Dai Yonghao. Study of blasting vibration control technology of up and down cross tunnel [J]. Rock and Soil Mechanics 2014, 35 (S2): 445-452.

[7] Yang Shan, Chen Jianhong, Guo Hongbin, Luo Zheng. Application of Regressive Analysis in the Research on Propagation Law of Tunnel Blasting Vibration [J]. China Safety Science Journal 2011, 21 (10): 71-75.

[8] Dhakal RP, Pan TC. Response characteristics of structures subjected to blasting-induced ground motion [J]. INT J IMPACT ENG 2003, 28 (8): 813-828.1.

[9] Qiu Xianyang, Shi Xiuzhi, Zhou Jian, Huang Dan, Chen Xin. On vibration reduction effect of short millisecond blasting by high-precision detonator based on HHT energy spectrum [J]. Explosion and Shock Waves 2017, 37 (1): 107-113.

[10] Zong Qi, Wang Haibo, Xu Ying, Fu Jugen. Analysis of blasting seismic wave signal in coalmine roadway excavation based on HHT method [J]. Journal of Vibration and Shock 2013, 32 (15): 116-120.

[11] GB 6722-2014 Safety regulations for blasting [S]. 2014.

[12] HUANG N E, SHEN Z, LONG S R. The empirical mode decomposition and Hilbert spectrum for nonlinear and nonstationary time series analysis [C] // Proceedings of the Royal Society. London: [s. n.]. 1998: 903-995.

[13] Shen J J, Yen W P, O'Fallon J. Interpretation and application of Hilbert-Huang transformation for seismic performance analyses [C] // Sixth US Conference and Workshop on Lifeline Earth-quake Engineering. Long Beach, CA, US: ASCE, 2003: 657-666.

[14] Li Xibing, Zhang Yiping, Liu Zhixiang. Wavelet analysis and Hilbert-Huang transform of blasting vibration signal $[\mathrm{J}]$. Explosion \& Shock Waves, 2005, 25 (6): 528-535.

[15] Qian Shouyi. HHT application research on blasting vibration sig-nal [D]. Changsha: Central South University, 2012. 